\title{
TEATRALIDAD Y MODOS DE REPRESENTACIÓN EN EL MELODRAMA DE RAINER W. FASSBINDER: DE SIRK A ARTAUD ${ }^{1}$
}

\author{
THEATRICALITY AND MODES OF REPRESENTATION IN THE MELODRAMA \\ OF RAINER W. FASSBINDER: FROM SIRK TO ARTAUD
}

\author{
Miguel OLEA-ROMACHO \\ Universidad de Granada \\ miguelolea@ugr.es
}

\begin{abstract}
Resumen: El presente artículo explora el concepto de teatralidad cinematográfica a partir de un análisis de la estética del melodrama y el estudio formal de la obra de uno de los principales renovadores del género, el director alemán Rainer Werner Fassbinder. En concreto, toma como referencia la película Todos nos llamamos Ali (1974) para examinar su recepción del melodrama clásico o sirkiano, demostrando que la filiación teatral del género no se debe simplemente al perfeccionamiento de los valores plásticos de la puesta en escena sino también a la importancia del cuerpo del actor o actriz como entidad de sentido privilegiada, y en el caso de Fassbinder, a la influencia combinada de Brecht y Artaud. El análisis está precedido por una valoración de la idea de teatralidad desde la teoría intermedial, así como de la relación del melodrama como género con el medio escénico.
\end{abstract}

Palabras clave: Teatralidad. Intermedialidad. Fassbinder. Melodrama. Sirk. Artaud. Brecht.

\begin{abstract}
This article deals with the concept of theatricality in film by studying the aesthetics of melodrama and discussing the work of one of the genre's most prominent renovators, German filmmaker Rainer Werner Fassbinder. Particularly, it centers on the film Ali: Fear Eats the Soul (1974) in order to explore its reception of classic or sirkian melodrama, proving that the theatrical nature of the genre is not merely due to the refinement of the plastic values of mise-en-scène and placing, but also to the importance of the performer's body as a privileged source of meaning, and, in Fassbinder's works, to the combined influence of Brecht's and Artaud's. Our analysis is introduced by a critical examination of the idea of theatricality from the perspective of Intermedial Theory and an exploration of the bonds between performing stage and melodrama as a genre.
\end{abstract}

Keywords: Theatricality. Intermediality. Fassbinder. Melodrama. Sirk. Artaud. Brecht.

\footnotetext{
${ }^{1}$ Este artículo es resultado de una investigación doctoral en curso en el marco del Proyecto I+D "Nar-Trans 2. Transmedialización y crowdsourcing en las narrativas de ficción y no ficción audiovisuales, periodísticas, dramáticas y literarias" (CSO2017-89657-P) (2018-2021).
} 


\section{LA TEATRALIDAD CINEMATOGRÁFICA: UNA CUESTIÓN INTERMEDIAL}

Si el cine en sus orígenes fue concebido como prolongación del teatro, aún sujeto a los códigos de representación de la frontalidad, el histrionismo de las interpretaciones, el artificio de los decorados y la mirada unipuntual del plano fijo, este empieza a formarse como medio autónomo a partir de las creaciones pioneras de Griffith y Eisenstein, que instauran el Modo de Representación Institucional (Burch, 1987). Desde entonces se consolida un cine narrativo basado en el montaje, la fragmentación de la escena completa en imágenes individuales y la pluralidad de perspectivas de la cámara, produciéndose un abandono sistemático de los modos del teatro en busca de la independencia artística del nuevo medio.

A partir de este primer momento, la idea de un cine teatral a menudo participa de una consideración del teatro como medio primitivo o antecedente lejano del cine, meramente convertido en rasgo de estilo de aquellas películas que destacan por lo artificioso de su estética. Se trata esta de una caracterización convencional que obvia las relaciones constitutivas que el medio cinematográfico establece con el teatro y que, más concretamente, definen el carácter de un cine moderno que subvierte los códigos de representación fílmicos para volver a los modos de la escena. De las múltiples tendencias que pueden diferenciarse en este momento de redescubrimiento teatral del medio - la diegetización del dispositivo escénico o la adaptación de obras teatrales, entre ellas - nos interesa especialmente el fenómeno de la teatralidad en ciertas películas contemporáneas que cultivan una "estética de la resistencia", en palabras de José Antonio Pérez Bowie (2010: 43).

Concretamente, el foco de nuestra atención lo ocupa el melodrama como género o modo de enunciación originalmente teatral asimilado con rapidez por el medio cinematográfico desde sus inicios. Desde hitos tempranos como Lirios rotos de D.W. Griffith (Broken Blossoms, 1919) o Avaricia de Erich von Stroheim (Greed, 1924) hasta cineastas contemporáneos como Todd Haynes o Lars von Trier, la trayectoria del melodrama cinematográfico es tan extensa como la nómina de directores cuyas películas se adscriben con facilidad a los "modos del exceso" (Brooks, 1976) que lo definen. No obstante, puede reconocerse un punto de inflexión claro en el recorrido del género, por el que ciertos autores lo recuperan en un movimiento de reteatralización que vuelve a ampliar el imaginario del melodrama en cine. Tomando como referente su edad dorada en Hollywood, y en especial la obra de Douglas Sirk, Rainer W. Fassbinder reformula los códigos del melodrama a través de la adopción explícita de recursos más propiamente escénicos que cinematográficos. El director emprende una renovación del género, que es devuelto a sus orígenes teatrales desde las posibilidades expresivas del cine y una abierta politización de sus estrategias narrativas y materiales ficcionales habituales. 
Así, nos proponemos explorar qué es la teatralidad cinematográfica, y en concreto, aquella asociada al nuevo melodrama de Fassbinder. Para ello, seleccionamos una película concreta, Todos nos llamamos Ali (Angst essen Seele auf, 1974), dadas las posibilidades de análisis que brinda en tanto que subversión y reformulación del melodrama sirkiano.

Para evitar incurrir en una formulación contenidista de la relación que une a teatro y cine, conviene adoptar un marco conceptual que pueda explicar con amplitud las relaciones concretas que unen a ambos medios. Tal y como señalan Domingo SánchezMesa y Jan Baetens (2017: 9), el comparatismo intermedial, en tanto que estudio relacional de la presencia de unos medios en otros, no solo se ocupa de la comprensión de las relaciones fronterizas entre ellos, sino también del carácter plural que los constituye internamente, con lo cual su especificidad nunca es homogénea o autónoma. Cada medio es resultado de su relación conflictiva con otros, y la heterogeneidad de elementos perceptivos y semióticos actúa siempre como condición de posibilidad de los mismos. Ello no supone, sin embargo, negar su especificidad, pues cada discurso atiende a una reconfiguración específica de esta pluralidad de lenguajes.

Del mismo modo, Jay D. Bolter y Richard Grusin establecen que todo medio es una "remediación" o "representación de un medio en otro" (1999: 45), de forma que este no se constituye de manera aislada sino en constante dialéctica con otros discursos. La formación de cada medio depende siempre de la interacción conflictiva entre discursos en relaciones de comentario, reproducción, sustitución, reformulación, etcétera. Esta noción resulta especialmente ilustrativa en la descripción del cine de Fassbinder, dado que no podemos reconocer las convenciones estéticas de sus películas más que a través de la referencia a otro medio, el teatro.

Por su parte, Irina Rajewsky (2005: 61) considera la remediación de Bolter y Grusin como un tipo particular de relación intermedial comprensible desde dos perspectivas distintas: por un lado, desde un punto de vista genealógico que explica la aparición de nuevos medios y, por otro, a partir del estudio de marcas concretas de remediación en objetos determinados. Para Rajewsky solo la segunda óptica tiene utilidad como categoría crítica, pues, al contrario que en el primer caso, en esta la remediación sí está asociada a la construcción de sentidos específicos y relevantes para la significación total del objeto en cuestión. Plantear aquí las relaciones históricas de remediación que el cine como medio emergente establece con el teatro carece de interés, no así el estudio de las referencias y rasgos concretos que constituyen un tipo de cine teatral en el caso de estudio.

Resulta útil recurrir a la tipología de relaciones intermediales formulada por Rajewsky para delimitar nuestro análisis. De los tres grupos ${ }^{2}$ diferenciados por la teórica nos

\footnotetext{
${ }^{2}$ Siguiendo la terminología propuesta por Rajewsky, un análisis más extenso sobre la teatralidad en la filmografía de Fassbinder debería comprender también las relaciones de transposición entre medios y las referencias intermediales. La transposición medial consiste en el desplazamiento de una obra desde un discurso a otro distinto, lo cual incluye el fenómeno de la adaptación. Son significativas en este aspecto las películas de Fassbinder basadas en obras teatrales anteriores, como Katzelmacher (1969) y Las amargas
} 
centramos en la "combinación de medios" (2005: 51-52), que responde a la articulación de dos o más discursos para constituir un nuevo producto específico. A su vez, Rajewsky diferencia entre las relaciones concretas de contigüidad entre medios y un proceso genuino de integración por el que la combinación medial tiene como resultado la creación de un objeto que no privilegia ninguno de sus elementos constitutivos. El estudio de la teatralidad de las películas de Fassbinder se enmarca dentro del primer grupo, puesto que la articulación de los discursos escénico y fílmico no conduce a la formación de un medio original, aunque sí se relaciona con una estética particular cuyo estudio proporciona información valiosa sobre las relaciones esenciales que se establecen entre ambos medios.

También es necesario advertir que la influencia del teatro trasciende las políticas de los autores para instalarse en el centro del medio cinematográfico. Como adelantábamos, la separación entre un cine primitivo de carácter teatral y un cine institucional esencialmente narrativo ha resultado en la minusvaloración de lo escénico como parte intrínseca del cine. Podemos relacionar estos dos momentos de la historia del medio con la distinción de André Gaudreault (1990: 32-36) de los dos regímenes de narratividad que se superponen en el lenguaje fílmico: la mostración, relacionada con la movilidad interna de los planos, y la narración, que comprende la combinatoria de los planos entre sí o, lo que es lo mismo, el montaje. En este análisis de los vínculos entre teatro y cine nos ocupamos sobre todo del primer régimen de narratividad enunciado por Gaudreault, si bien conviene diferenciar la mostración escénica de la mostración fílmica.

Frente a la copresencia física de actores y espectadores que demanda el medio teatral, el cine se funda sobre una comunicación mediata en la que la cámara guía y modifica la percepción de un espectador ausente durante el proceso de filmación. Ello no excluye, sin embargo, que el medio cinematográfico herede una noción teatral tan básica como la de escena. Anxo Abuín señala la impronta del teatro en el cine en el mantenimiento del concepto de escena como noción central, considerada como "el lugar imaginario donde se desarrolla la acción y se inscribe necesariamente la espacialidad como mímesis" (2012: 37). Por otra parte, aunque la del cine se trate de la llamada escena fría, ello tampoco impide que el medio incorpore formas de teatralización propiamente cinematográficas.

Así, buena parte del cine de Fassbinder se sitúa en lo que Pérez Bowie (2010: 43) considera como una fase distintiva de esta relación intermedial, marcada por la enfatización intencional de rasgos definidores de lo teatral: la artificiosidad de los decorados, el carácter antinaturalista de la iluminación, y en general, toda una serie de recursos de puesta en escena que explicitan el proceso y acto de enunciación. El teórico relaciona esta deriva estética con una idea postmoderna de la teatralidad, definida por Óscar Cornago como "la condición que una mirada aplica a un objeto por medio de la cual se introduce una distancia entre aquello que se está observando y lo que esa mirada

lágrimas de Petra von Kant (Die Bitteren tränen der Petra von Kant, 1972), versiones cinematográficas de sus propias obras de teatro. Las referencias intermediales son aquellas citas dentro del texto que aluden a otro medio. En este sentido, la aparición de la escena y el medio espectacular es una constante en su cine (La ley del más fuerte, 1975; Lili Marleen y Lola, 1981, entre otras). 
cree descubrir" (2001: 552). Según apunta Cornago, lo distintivo de la teatralidad reside en el hecho de que esta no se identifica con ninguno de los dos polos que integran esta relación de "presencia-ausencia", sino con el juego que se establece entre ambas partes, basado en "una tensión entre las presencias materiales que observamos y las ausencias que solo se dejan adivinar" (2001: 552). Si trasladamos estas consideraciones a nuestro objeto de estudio, podemos comprobar que la teatralidad cinematográfica es siempre un fenómeno intermedial en la medida en que tiene lugar entre dos sistemas expresivos diferenciados y no existe más que a través de la interrelación dinámica de estos. De tal forma, el carácter teatral del discurso cinematográfico depende siempre de las relaciones de proximidad entre los procedimientos de ambos medios.

Cuando Pérez Bowie clasifica cierto conjunto de películas como partícipes de una "estética de la resistencia" puede estar haciendo referencia a esta tensión entre lenguajes, por la que la integración de características teatrales y la preponderancia de la mostración se oponen a la inercia del medio fílmico hacia su versión institucional y expresamente narrativa. El efecto extrañante que resulta es también una consecuencia de la visibilidad de la instancia narradora, que impide cualquier sensación de realismo. Frente a la idea de la cámara como "gran imaginador" o "narrador invisible" (Gaudreault y Jost, 1990: 34), esta se descubre ahora como un dispositivo más involucrado en la creación de un aparato escénico; su presencia no pasa inadvertida, sino que se explicita deliberadamente a través de angulaciones y encuadres no convencionales y demás estrategias que respaldan la reivindicación de la materialidad del rodaje como acto de creación. Tal sería el principal rasgo definitorio de la teatralidad fílmica, que "desnuda la cámara del engaño de la ficción, asumiéndolo conscientemente, para transformarlo en la verdad material del acto performativo del rodaje" (Cornago, 2001: 555). También en el teatro la reteatralización es entendida como un movimiento que expone las reglas y convenciones de la representación, y según define Patrice Pavis, "presenta el espectáculo únicamente en su realidad de ficción lúdica" en contraposición al naturalismo, que "elimina al máximo las huellas de la producción teatral para dar la ilusión de una realidad escénica verosímil y natural" (1987: 472).

\section{SOBRE EL MELODRAMA Y LA TEATRALIDAD COMO CONVENCIÓN GENÉRICA}

Cornago (2001: 553) establece una relación de afinidad entre la teatralidad postmoderna en el cine y el teatro posdramático (Lehmann, 2017), categoría que comprende las realizaciones escénicas que se desarrollan al margen de los parámetros de la forma dramática para reivindicar el aspecto perceptivo del teatro en oposición a cualquier textocentrismo. Cabe precisar que, aunque la estética de Fassbinder pueda identificarse con esta preponderancia de lo performativo, sus películas siguen siendo filmes narrativos, en los que el relato está fuertemente condicionado por determinadas convenciones de género. En particular, Fassbinder es reconocido habitualmente como un 
gran renovador del melodrama. El cineasta adopta muchos de los recursos estilísticos del género en su versión clásica, pero desde una autoconsciente reelaboración crítica comparable a la que emprendieron Jean-Pierre Melville en Francia con el noir, Sergio Leone en Italia con el western (Carando, 2019: 72-73) o Takeshi Kitano en Japón con el cine de gánsteres. En su caso, Fassbinder problematiza el género trayendo a primer término su artificiosidad y reelaborando un estilo que, asociado al interior de los hogares burgueses en las obras de Douglas Sirk y Vincente Minnelli, no puede más que resultar antagónico en el retrato de la clase obrera y de las minorías que protagonizan la mayor parte de sus películas. No parece casual que un director considerado por lo general como teatral tenga intereses temáticos y genéricos tan definidos, de forma que merece la pena examinar la relación entre melodrama y teatralidad.

Tal y como apunta Peter Brooks, el término melodrama aparece por vez primera a finales del siglo XVIII para designar un tipo de drama acompañado por música y caracterizado por la búsqueda de "una nueva expresividad emocional a través de la mezcla del soliloquio, la pantomima y el acompañamiento orquestal" (1976: 14). Esta definición denota que el género se debe principalmente a una articulación de distintos sistemas sígnicos (el texto, el gesto y la música) que tiene por efecto una particular respuesta emocional. Se considera que las características principales del melodrama teatral son

un fuerte emocionalismo, el esquematismo y la polarización moral, la presentación extrema de situaciones, personajes y acciones, la persecución y recompensa final de la virtud, una expresión verbal extravagante y grandilocuente y los argumentos oscuros cargados de suspense (Brooks, 1976: 12).

El maniqueísmo que define al género es explicado por Brooks en términos socioculturales como una representación del universo moral de una "época desacralizada", marcada por el derrumbe de las instituciones monárquica y eclesiástica tras la Revolución Francesa. La disolución de los símbolos que aseguraban la pervivencia de una sociedad jerarquizada supone también el abandono de las formas literarias y escénicas que la representaban, como la tragedia y la comedia de costumbres. En su lugar, el melodrama representa tanto la necesidad de volver a sacralizar la sociedad como la aceptación de que la creación de los mitos y relatos explicadores ya no podía darse más que en términos personales e individuales (Brooks, 1976: 16). A esto se debe la caracterización unívoca de personajes y situaciones en el género, que toma como objetivo la designación clara del sistema de valores en que está inserto. Así, el bien y el mal podían nombrarse a través de personajes concretos en ficciones que probaban la existencia efectiva de un conjunto de reglas morales ante la incertidumbre provocada por la desaparición de los elementos cohesionadores que garantizaban el orden social anterior.

De tal modo, el juego de extremos del melodrama obedece a la representación casi pictórica de temas y valores en lo que Brooks llama "un drama de la vida moral" (1976: 12) basado en la exteriorización de los conflictos interiores de los personajes. Es por ello que es considerado como una forma opuesta al naturalismo, o bien, como "un naturalismo 
del mundo onírico" (Brooks, 1976: 35) indisociable de la idea de teatralidad y de la cuestión fundamental de la representación. Así lo admite Luchino Visconti, director de clásicos del género como Senso (1954) y uno de los principales referentes de Fassbinder ${ }^{3}$, al afirmar que "el melodrama toma forma en un punto intermedio entre la vida y el teatro" (cit. en Carando, 2019: 72), anteponiendo lo excesivo y arrebatado a las exigencias de la verosimilitud.

En su clasificación de la teatralidad cinematográfica, Pérez Bowie también distingue aquellas películas en las que lo teatral se incorpora de forma "natural" (2010: 45) porque así lo requieren las convenciones del género al que se adscriben. Este podría ser el caso del melodrama, cuyos rasgos teatrales fueron asimilados por el cine mudo a partir del desarrollo de un lenguaje formal que supliera la ausencia de diálogos y soliloquios, uno de los principales vehículos de la expresividad melodramática en el teatro. A partir de una serie de cambios en la iluminación, puesta en escena, interpretación y movimientos de cámara, Thomas Elsaesser (1972: 75) señala cómo directores como Murnau, Renoir, Mizoguchi o Sternberg lograron desarrollar una práctica cinematográfica que compensaba por completo la falta del diálogo en lo referente a la creación de suspense y la emotividad del melodrama. Tras la llegada del cine sonoro, la predominancia del texto oscureció los logros alcanzados por estos autores en cuanto a la plasticidad de la imagen y el valor de la puesta en escena, características que directores como Douglas Sirk, Nicholas Ray o Vincente Minnelli se proponen recuperar. El teórico apunta que estos cineastas, grandes representantes del melodrama hollywoodiense, comparten una concepción dramática de la puesta en escena basada en "el uso dinámico de categorías espaciales y musicales en detrimento de las intelectuales o literarias" (Elsaesser, 1972: 75).

Con ello, el diálogo es relegado a un elemento escénico más y el medio fílmico se imbuye de una forma de presentación espectacular que quizás alcanza un punto culminante en el cine de Sirk, y en particular en películas como Solo el cielo lo sabe (All That Heaven Allows, 1955), Escrito sobre el viento (Written on the Wind, 1956) e Imitación a la vida (Imitation of Life, 1959). Estos films representan bien un tipo de cine que depende en gran medida de la puesta en escena para relatar la historia y el mundo afectivo de los personajes, diluidos en componentes visuales y gestuales y en general, en toda una relación de recursos expresivos que sobrepasan al guion como elemento rector del significado.

Concretamente, apunta Elsaesser (1972: 77), Sirk sobresalió en la interrelación entre cualidades emocionales y texturas y materiales, ya fuese en relaciones de antagonismo o armonía. Su barroquismo visual queda como epítome de la teatralidad fílmica en el melodrama clásico por varios motivos. Por un lado, destaca su preferencia por espacios interiores, generalmente salones y salitas de estar de hogares burgueses cargados de

\footnotetext{
${ }^{3}$ Independientemente de las semejanzas entre la obra tardía de Visconti y el cine de Fassbinder, su admiración queda clara de forma suficiente al observar que La caída de los dioses (La caduta degli Dei, 1969) encabeza una lista de películas favoritas elaborada por el director (Fassbinder, 1981: 106).
} 
ornamentación. Lo ampuloso de los decorados se enfatiza aún más por medio de los colores saturados del Technicolor, la profusión de objetos y el uso continuo de la música para subrayar las respuestas emocionales de los personajes, que a menudo cuentan con sus propios leitmotiv. Además, es frecuente que las escenas se distingan por la frontalidad de su planificación, lo cual es reminiscente de la unipuntualidad de lo teatral frente a la pluralidad de perspectivas de lo fílmico.

Aunque la teatralidad de Sirk suele identificarse sobre todo con este modelo de puesta en escena, es preciso matizar que la consideración de un cine teatral debe atender necesariamente al cuerpo de los actores. Es habitual que las características espectaculares del cine sean identificadas solo desde los criterios del estatismo y lo pictórico, subestimando así la importancia de la presencia física del intérprete y las cualidades expresivas del gesto y el movimiento de los cuerpos. Lo teatral en el cine no solo se limita a un juego de apariencias que denuncia la naturaleza ilusoria de la imagen cinematográfica frente a las instancias materiales de la puesta en escena, sino que está determinado por la corporalidad del actor ante la cámara, que participa en lo que Elena del Río llama "una performance en movimiento continuo con el poder de deformar y transformar lo físico y lo estético, así como las dimensiones ideológicas de la película" (2008: 5).

Para ilustrar esta idea resulta útil recuperar un ejemplo analizado por Del Río, que comenta una de las escenas más célebres de Escrito sobre el viento. Hacia el final de la película, Marylee (Dorothy Malone), la díscola heredera del magnate del petróleo Jasper Hadley (Robert Keith), protagoniza una secuencia en la que baila en su habitación junto a la fotografía de Mitch (Rock Hudson), amigo de su hermano y empleado en el negocio familiar, al que ha amado de forma no correspondida desde la infancia. La escena tiene lugar justo después de que Marylee sea devuelta ante Hadley por la policía tras haber tenido un encuentro furtivo con un joven de clase obrera, lo cual supone un acto de provocación y un intento de desestabilizar el orden familiar impuesto por su padre. Después de que Hadley interrogue al joven sobre la promiscuidad de su hija y lo expulse del complejo, Marylee reproduce en el tocadiscos de su habitación una canción de sonido latino a todo volumen.

A partir de este momento el montaje en paralelo muestra que, al mismo tiempo que Marylee baila frenéticamente al ritmo de la música, Hadley tiene un colapso y muere después de caer por las escaleras. Del Río destaca cómo el montaje y la banda sonora en esta secuencia establecen una relación de causalidad entre la exhibición desenfrenada de corporalidad de Marylee y el abatimiento del padre, argumentando que, aunque el baile se enmarca dentro de la rigidez de diversos binarismos de género (como son su frustración sexual y emocional dentro de una cultura patriarcal, la ira contra su padre y una reacción a su deseo no correspondido por Mitch), este se convierte en una fuerza en sí misma que, desprovista de toda causa, es capaz de provocar la muerte de Hadley (Río, 2008: 54). De tal forma, la presencia física de la actriz tiene la capacidad de alterar el relato únicamente por medio del movimiento y la exhibición del cuerpo, aunque finalmente la película 
reinstaure el orden ideológico que la escena parece subvertir, pues Marylee desiste de sus esfuerzos por conquistar a Mitch y se resigna a continuar el legado familiar como cabeza de la empresa.

\section{SIRK / BRECHT / ARTAUD: TODOS NOS LLAMAMOS ALI (1974)}

El redescubrimiento del cuerpo es determinante en un momento de reinvención performativa del cine, por el que las acciones y la presencia física significan en sí mismas en tanto tales. Gilles Deleuze (1985: 255) utiliza el término brechtiano de gestus para referirse a este entramado de actitudes corporales, una teatralización del cuerpo que se interpone a la propia intriga del film. La escena de la película de Sirk evidencia cómo el cuerpo de los intérpretes se convierte en una instancia expresiva privilegiada, capaz incluso de rebasar los límites ideológicos del relato.

Deleuze amplía el concepto de gestus precisando que, además de ser "necesariamente social y político, también es biovital, metafísico, estético" (1985: 258). Pero en la teoría brechtiana, el gestus implica un esfuerzo por representar o copiar gestos bajo los que subyace una determinada situación socioeconómica y política que da forma a la identidad, y en concreto, "se compone de un simple movimiento de una persona hacia otra, de una manera social o corporativamente particular de comportarse" (Pavis, 1987: 244-245). En la intersección de estas dos acepciones de gestus se emplaza el melodrama de Fassbinder. Además de ser un exponente claro de lo que Deleuze llama un "cine del cuerpo" en el que "el personaje se reduce a sus propias actitudes corporales" (1985: 255) de forma que este es más un compendio de gestos que una entidad abstracta y preconcebida de rasgos psicológicos, el director también se acerca a un entendimiento más propiamente brechtiano del concepto en cuanto que bajo los movimientos y expresiones de sus personajes subyacen a menudo "comportamientos comunes de un grupo o actitudes colectivas de clase" (Pavis, 1984: 293) .

Precisamente, Fassbinder inicia su trayectoria artística en el Antiteater, grupo que trasladaba las tesis brechtianas al teatro alemán de finales de los sesenta y que "se entendía a sí mismo como un teatro de corte socialista que pretendía provocar y desconcertar, y al mismo tiempo, informar y educar a su público" (Gemünden, 1994: 60). La teatralidad de su cine puede asimismo explicarse desde una intención de generar conciencia crítica en el espectador por vía de un carácter artificial de la representación; las elaboradas composiciones visuales a la manera del melodrama sirkiano son empleadas para detener el avance de la acción e ilustrar las relaciones de poder entre los personajes, de modo que los cuadros escénicos de Fassbinder se acercan más a la definición de teatralidad propuesta por Cornago en su carácter autorreflexivo. Según apunta Elsaesser, el artificio

\footnotetext{
${ }^{4}$ Pavis aclara que el gestus no lleva a un uso de lo gestual propio del teatro de títeres, en el que cualquier movimiento cobra la función de un signo dentro de una visión sociológica fijada y estricta del comportamiento humano, sino que este interpela a actor y espectador de forma que "estén siempre invitados a seleccionar detalles del gesto que revelen una conducta social” (1984: 297).
} 
le permitió al director marcar las diferencias entre los elementos de la ficción que podían haber sido extraídos de la realidad "y los que el espectador podía reconocer de otras películas, ya fueran melodramas de Hollywood, películas vanguardistas de bajo presupuesto o telenovelas" (1996: 51).

La generación post-Mayo del 68 en Alemania guardaba una actitud de sospecha hacia las producciones culturales americanas y la estética de Hollywood, y tanto las primeras películas de Fassbinder - films de gánsteres más cercanos al cine de Godard y StraubHuillet, como El amor es más frío que la muerte (Liebe ist kälter als der Tod, 1969) o El soldado americano (Der Amerikanische Soldat, 1970) - como sus melodramas posteriores pueden entenderse a la manera de una investigación sobre las contradicciones históricas y psicológicas del rol de la cultura popular estadounidense en la conformación del imaginario creativo de la generación de postguerra. No es por ello de extrañar que el pensamiento brechtiano fuera una de las influencias decisivas del Nuevo Cine Alemán, tanto para Fassbinder como para Alexander Kluge, Hans Jürgen Syberberg, Harun Farocki, Jean-Marie Straub y Danielle Huillet, Helma Sanders-Brahms o Margarethe von Trotta. Todos ellos compartieron la búsqueda de un espectador activo capaz de tomar posición ante lo que ve, una actitud crítica que el teatro épico de Brecht logró por medio de la técnica del distanciamiento, consistente en una forma anti-mimética que permite la objetivación ideológica de la obra e impide cualquier ilusión de representación o implicación emocional con los personajes.

En su cine puede observarse una serie de rasgos formales que, deudores de la puesta en escena del melodrama americano, cobran una función crítica desde esta óptica distanciada: el predominio casi total de interiores frente a exteriores, las actuaciones antinaturales, la falta de profundidad en el plano, una composición escenográfica colorista, la elección de puntos de vista imposibles para la cámara, a cuya mirada se interponen cristales o espejos, o el encuadre de los personajes en el interior del plano, pues sus figuras son a menudo enmarcadas por el contorno de puertas y ventanas. Mario de la Torre-Espinosa destaca otras características fundamentales de la estética teatral del director, como el uso de la luz para producir efectos sobre los personajes, y la dirección de actores como "volúmenes en ocasiones ubicados en el plano atendiendo únicamente a su valor plástico" (2020: 147). Thomas E. Erffmeyer (1983: 38) reconoce que la originalidad de tales recursos, por lo demás habituales en el contexto del cine moderno y los nuevos cines, reside en la manera en que son empleados desde el marco de un género popular como el del melodrama ${ }^{5}$. Por su parte, Gerd Gemünden acierta en señalar que la formulación clásica del género no está de ningún modo desprovista de cierto carácter crítico, afirmando que Fassbinder no se recrea simplemente en el artificio desde una estética brechtiana para politizar el melodrama, sino que apela a su "carácter subversivo

\footnotetext{
${ }^{5}$ Por otro lado, es interesante destacar que, como expone Roswitha Mueller, la distancia entre Brecht y la forma melodramática no es tanta cuando se considera que ambos centran su interés en la vida de la gente corriente, enfatizan la polarización entre el bien y el mal y recurren con frecuencia a la parábola (cit. en Gemünden, 1994: 70). Ello no hace, sin embargo, que la importancia concedida a la subjetividad afectiva de los personajes del melodrama y las experiencias colectivas del teatro épico sean más reconciliables.
} 
intrínseco para hacer que el público reevalúe su percepción estereotipada de las películas de Hollywood como apolíticas" (1994: 75). El teórico alude que el director encontró en Sirk una sensibilidad camp capaz de combatir el exceso racionalista y conformista de la modernidad, aunque marca distancias entre la estética de este melodrama clásico y el "camp intencional" de Fassbinder (Gëmunden, 1994: 73), basado en la recuperación consciente de los recursos anti-naturalistas del cine de Sirk.

Según anticipábamos, los rasgos característicos de la puesta en escena de los melodramas de Fassbinder coinciden con aquellos que definen el movimiento de "reteatralización postmoderna" que Pérez Bowie enuncia basándose en la definición aportada por Cornago, afirmando que en el cine una teatralidad premeditada

se convierte en un modo de denuncia de la dimensión ficcional del universo diegético y que en el fondo están las teorías brechtianas sobre la necesidad de quebrar la ilusión alienante mediante estrategias distanciadoras (2010: 44).

De forma análoga, el mismo Brecht defiende una reteatralización de la escena al insistir en la necesidad del "restablecimiento de la realidad teatral como como condición necesaria para que puedan ofrecerse imágenes reales de la vida entre los hombres" (cit. en Pavis, 1987: 472). No obstante, tal perspectiva no contempla la importancia del cuerpo del intérprete en la relación intermedial que une al teatro y al cine, quedando reducida a una cualidad puramente pictórica o basada en la creación de extrañantes tableaux vivants. Si atendemos a una lectura unívoca de la obra de Fassbinder a partir de Brecht, quizás caigamos en el riesgo de admitir que en sus películas la composición de cuadros y una estética artificiosa hacen que la corporalidad del actor sea abstraída de su movilidad e inestabilidad propias para mostrar su sometimiento inconsciente a determinadas estructuras ideológicas.

Por ello, resulta difícil trazar un parentesco completo entre la teatralidad de Fassbinder y el distanciamiento brechtiano que parece sustentar estos rasgos estéticos, pues tal enfoque se desprende del papel decisivo del cuerpo en la conformación de un cine teatral. Además, las actuaciones excesivas de las películas de Fassbinder suelen identificarse con una emotividad desbordante tomada del melodrama clásico y que contradice los presupuestos brechtianos. Aunque algunos afirmen que "la interpretación estilizada y los amanerados diálogos de sus películas hagan que sea difícil comprometerse emocionalmente con los personajes" (Gemünden, 1995: 78), Fassbinder siempre contó en sus melodramas con una doble intención, la de "unir algo tan hermoso y poderoso como las películas de Hollywood con una crítica al status quo" (Fassbinder cit. en Gemünden, 1994: 55). Estos se enmarcan en un segundo momento de la filmografía del director, posterior al fracaso de los movimientos estudiantiles, en el que se separa del brechtianismo estricto de Godard y Straub-Huillet y busca el género melodramático con el fin de llegar a públicos más amplios.

Elena del Río ahonda en esta evolución al afirmar que, mientras que para Brecht las emociones debían estar siempre sujetas a una aproximación crítica, "Fassbinder concibe 
la relación entre lo social y lo emocional en términos de implicación mutua" (2008: 70). Así, el director bávaro considera que "con Brecht, ves las emociones y te proyectas en ellas, pero no las sientes" (Fassbinder cit. en Sparrow, 1977: 20), afirmación que sugiere cómo a partir de cierto punto su cine se distancia del pensamiento del dramaturgo en favor del énfasis melodramático en la experiencia individual. Del Río (2008: 73) va más allá en la descripción de esta transformación al relacionarla con la influencia que Artaud y el teatro de la crueldad ejercen sobre la obra de Fassbinder. El teórico se preguntaba cómo era posible que el teatro occidental hubiera relegado a último término todo lo específicamente teatral, es decir, todo aquello que no obedece a la expresión de palabra o no cabe en el diálogo. La expresión teatro de la crueldad da nombre a un proyecto de representación capaz de llevar al espectador a experimentar un "tratamiento emotivo de choque" (Pavis, 1987: 481) que lo liberase del dominio del pensamiento lógico y le permitiera alcanzar una experiencia estética original. Así, para Artaud la escena es un espacio físico no supeditado al texto o a un discurso previo, cuyo lenguaje está compuesto por todo aquello que se manifiesta materialmente sobre ella y en especial por la voz, los gestos y movimientos del cuerpo, implicando al espectador por una vía sensorial y no intelectual. Derrida define el concepto artaudiano de puesta en escena como "la materialización plástica y visual del discurso", compuesta por "todo aquello que puede decirse sobre la escena independientemente de la palabra" (1985: 240).

Este modelo dialoga bien con las definiciones de melodrama ofrecidas por Brooks y Elsaesser y apuntadas más arriba, que comprenden el género como una exteriorización de los afectos a partir de la interrelación de un conjunto de lenguajes que exceden lo puramente textual o literario. Sin dejar de reconocer la impronta brechtiana de su cine, Del Río establece una filiación directa entre lo melodramático en la obra de Fassbinder y el teatro de la crueldad, lo cual resulta en una combinación particular de influencias: mientras que de Brecht toma la intención de provocar la reflexión al espectador por medio de recursos distanciadores, esta crítica es entendida en términos físicos y performativos, "como un proceso corporal y no como una construcción puramente abstracta" (Río, 2008: 75-76). Igualmente, Eric Rentschler afirma que su cine es el mayor exponente de una "política del cuerpo" (Körperpolitik) del Nuevo Cine Alemán, una práctica que privilegia "el impacto directo sobre la retórica, lo tangible por encima de lo discursivo" (1985: 196). Fassbinder entró en contacto con los postulados de Brecht durante su período en el Antiteater, pero también experimentó previamente con el teatro de la crueldad después de su entrada en el Action Theater, una compañía alemana formada en la influencia de The Living Theatre. Gemünden reconoce que la influencia de estos dos métodos aparentemente contrapuestos se materializó en su producción teatral con el Antiteater en un estilo único, que combinaba rasgos típicamente brechtianos como los argumentos episódicos, el didactismo, el rechazo de las explicaciones psicologistas y un estilo sobrio y estilizado de actuación "con la violencia, energía y espontaneidad artaudianas" (1994: 61). Del mismo modo, Michael Töteberg afirma que "el Antiteater desarrolló un nuevo 
tipo de obra que integraba los distintos esfuerzos de Artaud y Brecht de forma más convincente que The Living Theatre" (cit. en Gëmunden, 1994: 61).

Dicha suma de métodos no se restringe a su trabajo en el teatro, y como indica Patricia Carbonari, en su filmografía la impronta de Brecht se deja ver en "la firme convicción de distanciar al actor del personaje y a este del público" (2018: 283) y la de Artaud queda patente en la forma en que "ambos buscan dinamizar el concepto de puesta en escena e ir en contra del utilitarismo del lenguaje" (2018: 278). En una línea similar, Horacio Muñoz Fernández coincide en apuntar que "la crítica ideológica y social que realiza el cineasta alemán a través del gestus de sus personajes, aparece vinculada a una concepción artaudiana de la corporalidad como fuerza histérica y excesiva" (2018: 126).

Comprobemos la pertinencia de estas tesis en un ejemplo, Todos nos llamamos Ali. La película adapta el clásico de Sirk Solo el cielo lo sabe, si bien radicaliza el original al hacer emerger toda una red de subtextos ocultos en el melodrama hollywoodiense. De hecho, podríamos ya advertir el carácter brechtiano del film al considerar que el conflicto básico es planteado en los términos de una fábula moral alrededor del rechazo de la alteridad y de la violencia racista y misógina ejercida sobre los personajes principales. Los protagonistas y sus perseguidores actúan como unidades significantes de un determinado tejido social, el de la xenofobia de un país aún vinculado estrechamente a su pasado reciente, de modo que el film puede considerarse como "una parábola social sobre la sociedad alemana del momento" (Gemünden, 1994: 70-71). No obstante, esta crítica no se formula a través de un rígido esquematismo y la relevancia transformadora del cuerpo de los actores no es de ningún modo anecdótica.

La película está protagonizada por Emmi (Brigitte Mira) una limpiadora de sesenta años y viuda, y Ali (El Hedi ben Salem), un gastarbeiter marroquí veinte años menor que ella. Después de que ambos se enamoren y contraigan matrimonio, tanto la familia como los conocidos de Emmi y las amigas de Ali repudian su unión, siendo la pareja evitada y provocada constantemente. Cuando Emmi presenta a Ali a sus hijos y después de que este los salude con una reverencia, la cámara se desplaza de izquierda a derecha para filmar en primer plano sus rostros paralizados. Tras esto, uno de ellos se levanta y destroza una televisión a patadas, liberando así la agresividad que todos parecían contener.

Esta escena es una reelaboración de una secuencia similar de Solo el cielo lo sabe, en la que los hijos de la viuda Cary (Jane Wyman) le regalan una televisión después de haber desaprobado su relación con Ron (Rock Hudson), un jardinero más joven que ella. Mientras que en el film de Sirk el rechazo de los hijos y la soledad de la protagonista es simbolizado a través de este elemento escenográfico, con la escena terminando en un plano en el que Cary aparece atrapada en su propio reflejo en la pantalla del aparato, la propuesta de Fassbinder, en una solución completamente artaudiana, resuelve la situación mediante un gesto imprevisto y extremo que desestructura el estatismo de la puesta en escena y suspende la narrativa en pos de la pura expresividad corporal.

La secuencia da también muestras de otra característica habitual del cine de Fassbinder, la presencia de personajes secundarios que no intervienen en la acción más 
que para presenciar los acontecimientos, a la manera de "instancias de la mirada" (Elsaesser, 1996: 65). El director parece conceder una importancia capital a la visión y el acto de mirar, que nunca está motivado por las exigencias narrativas del desarrollo del relato. Elsaesser (1996: 60) reconoce que en su cine todas las relaciones interpersonales, el contacto físico y las jerarquías sociales se manifiestan en torno a la relación ver/ser visto, si bien el teórico aclara que tal binomio no se da en términos neutrales o de reversibilidad completa entre sus dos componentes. Por el contrario, se relaciona con unas dinámicas de poder por las que son siempre aquellos privilegiados culturalmente los que ostentan el poder de la mirada, que tiene la capacidad de alienar a los sujetos observados. Así, no hay ningún lugar en el que Ali y Emmi no se enfrenten a las miradas hostiles de la comunidad, y el encuadre obsesivo de ambos personajes dentro del plano confirma que su relación está siempre sujeta a esta vigilancia. La vulnerabilidad de la pareja ante las miradas insidiosas de los vecinos se convierte en el motivo escénico que articula la acción a lo largo de la película, y el carácter sistémico de tal violencia es evidente en el comportamiento gregario de quienes observan. Ello resulta claro en la escena en que Ali y Emmi se reúnen en una terraza bajo el acecho de un grupo de personas que incluye a los camareros del bar, un matrimonio de ancianos y dos jóvenes, un hombre y una mujer. La variedad demográfica del conjunto y el hecho de que todos se comporten de la misma manera, manteniendo una postura hierática y una mirada despreciativa fijada en los dos amantes, aislados en el centro de la plaza, pone de manifiesto que la humillación que sufren dista mucho de ser casual. La dirección de actores en esta secuencia responde al concepto brechtiano de gestus en la medida en que este es siempre social y da nombre a "las actitudes que los personajes adoptan los unos respecto a los otros" (Brecht en Pavis, 1987: 244) y al "tipo de relación fundamental que rige los comportamientos sociales (servilismo, igualdad, violencia, astucia, etc.)" (Pavis, 1987: 245).

Pero también podríamos considerar que esta dualidad entre observadores y observados se traduce en un dispositivo espectatorial que hace de la pareja protagonista un dúo de performers, pues es precisamente bajo las miradas excluyentes de los demás cuando ambos reconocen su diferencia y reafirman su identidad. Ello es evidente en las escenas de baile en el bar, dos secuencias que marcan el primer encuentro y la reconciliación posterior. Es significativo que los momentos de mayor unión entre Ali y Emmi se identifiquen con estas escenas, en las que la presencia física de los enamorados ejerce como un acto de resistencia irreductible frente a la discriminación que sufren. En este sentido, Fassbinder vuelve a acercarse a Artaud desde un tratamiento del cuerpo como entidad "material, irracional y prelingüística capaz de combatir la automatización ideológica” (Río, 2008: 75) impuesta por la comunidad. La alternancia de planos muestra a la pareja bailando en solitario e iluminados solamente por una luz roja y al resto de gente del bar, que los observa atentamente. La planificación de estas escenas parece establecer una relación de continuidad entre la historia amorosa de Ali y Emmi, representada en términos físicos mediante el baile, y la censura impuesta por su entorno social, de tal modo que la teatralización del propio cuerpo es una manera de ilustrar la 
forma en que ambos fortalecen su relación al ser capaces de reconocer su condición compartida de sujetos no normativos cuando son percibidos como tales por los demás. Si, tal y como hace ver Del Río, en Escrito sobre el viento la corporalidad de la actriz lograba subvertir el entramado ideológico de la película de manera accidental, en Todos nos llamamos Ali la escenificación del cuerpo se asume como herramienta crítica de forma consciente.

En la segunda escena de baile y justo antes del final de la película, Ali se desploma sobre la pista y comienza a retorcerse y gemir de dolor. Este hecho podría interpretarse en primera instancia como un coup de théâtre o suceso imprevisto que cambia de repente la acción dramática, definido por Samuel Weber en términos artaudianos como "un golpe, algo que de forma más o menos violenta interrumpe el desarrollo de los acontecimientos y cuestiona la unidad de sentido, de acción, y, sobre todo, de tiempo y espacio" (2000: 17-18). Sin embargo, durante la última escena conocemos las razones de este colapso cuando en el hospital un médico le comunica a Emmi que Ali tiene una úlcera de estómago, una dolencia propia de los trabajadores extranjeros y ocasionada por el estrés. El doctor reconoce la incapacidad del sistema de salud de ayudar a los gasterbeiter, a los que no se les permite ser hospitalizados y cuya única alternativa es la cirugía, que prueba ser inútil después de seis meses. El final de Todos nos llamamos Ali es un buen ejemplo de la tensión existente entre las influencias del teatro de la crueldad y el gestus brechtiano en el cine de Fassbinder: si en principio el colapso de Ali parecía ser una demostración corporal completamente disruptiva y autorreferencial, en última instancia el cuerpo es resemantizado como un signo en el que tiene lugar la intersección entre determinadas estructuras ideológicas y la respuesta material e individual hacia estas formas de opresión.

\section{CONCLUSIONES}

La aproximación intermedial al concepto de teatralidad cinematográfica nos ha ayudado a comprender el género del melodrama como uno indisociablemente unido a estrategias propias del medio escénico, tales como la atención a los valores plásticos en la composición de la imagen $\mathrm{y}$, sobre todo, la relegación del texto a otro elemento escénico más. Fassbinder renueva el género a partir de una reteatralización que enfatiza el valor performativo del film en detrimento del carácter ilusorio de la estética cultivada por el melodrama clásico y, en especial, por el cine de Sirk. Su obra no está tan lejos de los principios del género en su formulación tradicional, dado que este siempre se basó en la representación deliberada de temas, emociones y sentimientos mediante lo que podríamos llamar una semantización absoluta de los elementos de la puesta en escena. Sin embargo, el movimiento de reformulación estético de Fassbinder con respecto a Sirk reside en el subrayado consciente de estos recursos, que resulta en la creación de un cine teatral entendido según los términos de la estética de la resistencia definida por Pérez Bowie y Cornago. 
Aun teniendo en cuenta la importancia de las estrategias de distanciamiento brechtianas en las que se apoya este tipo de cine, una valoración justa de su carácter teatral debe también comprender la reflexión sobre el cuerpo del intérprete y su presencia material frente a la cámara, a menudo instrumento de denuncia política. Por ello, resulta conveniente completar las consideraciones sobre las películas de Fassbinder atendiendo también a la herencia artaudiana que ostentan, siendo esta una forma adecuada de reconocer cómo el cine logra acercarse a la fisicidad del teatro y las realizaciones escénicas a través de sus propios medios expresivos. El ejemplo de Fassbinder puede ayudar a repensar la idea de un cine teatral más allá de consideraciones reductoras que limitan la relación entre ambos medios al empleo de elementos distanciadores y antimiméticos, invitando a expandir un concepto que solo tiene sentido en la medida en que comprende la presencia física del actor y la actriz y los efectos que esta genera.

\section{REFERENCIAS BIBLIOGRÁFICAS}

ABuín, A. (2012). El teatro en el cine. Madrid: Cátedra.

Bolter, J. D. \& Grusin, R. (1999). Remediation - Understanding New Media. Massachusetts: Mitt Press

Brooks, P. (1976). The Melodramatic Imagination. New Haven: Yale University Press. BurCH, N. (1987). El tragaluz del infinito, F. Llinás (trad.). Madrid: Cátedra.

CARANDO, V. (2019). "Más frío que la muerte. El melodrama según Fassbinder: un itinerario crítico". En Rainer Werner Fassbinder. Amor y Rabia, Q. Casas (coord.), 71-78. San Sebastián: Euskadiko Filmategia.

CARBonari, P. (2018). "Fassbinder entre bambalinas. El poderoso camino entre Artaud y Brecht”. En Rainer Werner Fassbinder. Solo quiero que me amen, J. Rodrigo García (coord.), 274-293. Madrid: Shangrila.

CORNAGO, Ó. (2001). "Diálogos a cuatro bandas: teatro, cine, televisión y teatralidad". En Del teatro al cine y la televisión en la segunda mitad del siglo XX, J. Romera Castillo (ed.), 549-560. Madrid: Visor Libros.

Deleuze, G. (1985). La imagen-tiempo, I. Agoff (trad.). Barcelona: Paidós.

DERrIDA, J. (1978). "The Theater of Cruelty and the Closure of Representation". En Writing and Difference, 232-250. Chicago: University of Chicago Press.

Elsaesser, T. (1972). "Tales of Sound and Fury: Observations on the Family Melodrama”. En Imitations of Life. A Reader on Film \& Television Melodrama, M. Landy (ed.), 68-91. Detroit: Wayne State University Press.

(1996). Fassbinder's Germany. History, Identity, Subject. Amsterdam: Amsterdam University Press.

ERFFMEYER, T. E. (1983). "I Only Want You to Love Me: Fassbinder, Melodrama and Brechtian Form". Journal of the University of Film and Video Association 35.1, 37-43. 
FASSBINDER, R. W. (1981). "The List of My Favorites". En The Anarchy of Imagination. Interviews, Essays, Notes from Rainer Werner Fassbinder, M. Töteberg y L.A. Lensing (eds.), 106-108. Londres: The Johns Hopkins University Press.

Gaudreault, A. Y Jost, F. (1990). El relato cinematográfico, N. Pujol (trad.). Barcelona: Paidós.

Gemünden, G. (1994). "Re-Fusing Brecht: The Cultural Politics of Fassbinder German Hollywood". New German Critique 21, 55-75.

(1995). "Brecht y Hollywood en el cine de R.W. Fassbinder". Revista de Occidente $175,67-94$.

Lehmann, H. T. (2017 [1999]). Teatro posdramático, D. González (trad.). Murcia: CENDEAC.

MuÑOZ FERNÁNDEZ, H. (2018). "Estética teatral (masoquista) en Las amargas lágrimas de Petra Von Kant (1972)". En Rainer Werner Fassbinder. Solo quiero que me amen, J. Rodrigo García (coord.), 123-135. Madrid: Shangrila.

Pavis, P. (1984). “On Brecht's Notion of Gestus”. En Semiotics of Drama and Theatre. New Perspectives in the Theory of Drama and Theatre, H. Schmid \& A. Van Kesteren (eds.), 290-304. Amsterdam / Philadelphia: John Benjamins Publishing Company.

(1987). Diccionario de teatro. Dramaturgia, estética, semiología. Barcelona: Paidós.

PÉrez Bowie, J. A. (2010). "La teatralidad en la pantalla. Un ensayo de tipología". Signa 19, 35-62. Disponible en línea: https://doi.org/10.5944/signa.vol19.2010.6227 [23/03/2020].

RAJEWSKY, I. (2005). "Intermediality, Intertextuality and Remediation: A Literary Perspective on Intermediality". Intermédialité - Historie et théorie des arts, des lettres et des techniques 6, 43-64.

RENTSCHLER, E. (1985). “Terms of Dismemberment: The Body in/and/of Fassbinder's Berlin Alexanderplatz". New German Critique 34, 194-208.

Río, E. del (2008). Deleuze and the Cinemas of Performance. Powers of Affection. Edimburgo: Edinburgh University Press.

SÁNCHEZ-MESA, D. y BAETENS, J. (2017). "La literatura en expansión. Intermedialidad y transmedialidad en el cruce entre la literatura comparada, los estudios culturales y los new media studies". Tropelías 27, 6-27. Disponible en línea: https://doi.org/10.26754/ojs_tropelias/tropelias.2017271536[02/02/2020].

Sparrow, N. (1977). "I Let the Audience Feel and Think: An Interview with Rainer Werner Fassbinder". Cinéaste 8.2, 20-21.

TORRe-Espinosa, M. DE LA (2020). Almodóvar y la cultura. Gijón: Ediciones Trea.

Töteberg, M. \& Lensing, L. A., EDS. (1992). The Anarchy of Imagination. Interviews, Essays, Notes from Rainer Werner Fassbinder, K. Winston (trad.). London: The Johns Hopkins University Press. 
WeBER, S. (2000). "The Greatest Thing of All: The Virtuality of Theatre". En 100 Years of Cruelty: Essays on Artaud, E. Scheer (ed.). Sydney: Power Publications and Artspace.

(c) $\left(\begin{array}{l}\text { This work is licensed under a Creative Commons Attribution- } \\ \text { BY }\end{array}\right.$

Fecha de recepción: 16/01/2021

Fecha de aceptación: 23/06/2021 